\title{
Kolaborasi Pembangunan Desa Berkelanjutan Melalui Program Dana Desa Di Kecamatan Sokaraja Kabupaten Banyumas
}

\author{
Andi Antono ${ }^{1}$, Mahmud Setiahadi $^{2}$, Ngalimun $^{3}$ \\ ${ }^{123}$ Fakultas Ilmu Sosial dan Ilmu Politik, Universitas Jenderal Soedirman, Jl. Prof. Dr. H.R \\ Boenyamin No. 993 Purwokerto 53122
}

\begin{abstract}
Village funds which have become a pendulum for village development provide quite a formidable task for village village administrators to make the best use of them. The involvement of public and community actors at the local level is a strategic step in managing village funds to provide a transparent and accountable effect, as mandated by the collaborative governance model so that the results of development become more beneficial for the citizens. This research uses a qualitative method. The technique of taking informants is done by snowball sampling while maintaining independence in expressing opinions. Data collection methods with in-depth interviews, observation and document analysis. Data analysis was carried out interactively, starting from data collection, data condensation, data appearance, and research conclusions drawn and combined with the appearance of descriptive data.The results showed that the collaborative process had proceeded well as seen from face-to-face dialogue, building trust, community commitment and various understandings of the development had an impact on effective development outcomes both physical and non-physical in nature.
\end{abstract}

Keywords: collaborative governance, village funds, rural development

\begin{abstract}
Abstrak
Dana desa yang menjadi pendulum pembangunan desa memberikan tugas yang cukup berat bagi perangkat desa untuk memanfaatkannya dengan sebaik-baiknya. Pelibatan aktor masyarakat dan masyarakat di tingkat lokal merupakan langkah strategis dalam pengelolaan dana desa agar memberikan efek yang transparan dan akuntabel, sebagaimana diamanatkan oleh model tata kelola kolaboratif agar hasil pembangunan menjadi lebih bermanfaat bagi warga. Penelitian ini menggunakan metode kualitatif. Teknik pengambilan informan dilakukan dengan snowball sampling dengan tetap menjaga kemandirian dalam menyampaikan pendapat. Metode pengumpulan data dengan wawancara mendalam, observasi dan analisis dokumen. Analisis data dilakukan secara interaktif, dimulai dari pengumpulan data, kondensasi data, tampilan data, dan kesimpulan penelitian yang ditarik dan dipadukan dengan tampilan data deskriptif. Hasil penelitian menunjukkan bahwa proses kolaboratif telah berjalan dengan baik, terlihat dari dialog tatap muka, membangun kepercayaan, komitmen masyarakat dan berbagai pemahaman tentang pembangunan berdampak pada hasil pembangunan yang efektif baik fisik maupun non fisik.
\end{abstract}

Kata kunci: collaborative governance,dana desa, pembangunan desa

\footnotetext{
${ }^{*}$ Penulis Korespondensi

E-mail : andiantono611@gmail.com
} 


\section{PENDAHULUAN}

Pembangunan desa yang berkelanjutan merupakan kegiatan pembangunan yang terjadi pada masyarakat desa yang dipicu oleh keinginan untuk maju dan memungkinkan terjadinya pertumbuhan ekonomi yang terus menerus disertai dengan pemerataan sehingga dalam jangka panjang akan terjadi efek simultan antara petumbuhan ekonomi, peningkatan konsumsi masyarakatdan tabungan masyarakat desa setempat menuju pada pemberdayaan. Pemberdayaan dalam masyarakat hendaknya ditekankan terus menerus untuk melahirkan kemandirian dan otonomi warganya, sebagaimana dituangkannya undang-undang desa.

Menurut Soleh (2014), terdapat 4 prinsip yang harus dijadikan pegangan dalam pembangunan pemberdayaan hendaknya dijalankan secara terarah dan ditujukan secara langsung kepada yang memerlukan, program sengaja dirancang untuk memecahkan masalah, sesuai dengan kebutuhannya, dan aktor utama penyusunan, pelaksanaan program/proyek adalah masyarakat sendiri dan penggunaan pendekatan kelompok, karena secara individual, masyarakat miskin sulit memecahkan masalah-masalah yang dihadapinya.

Pelaksanaan pembangunan yang berdimensi pada pemberdayaan memberikan peluang yang besar bagi masyarakat dan aktor kelembagaan di desa untuk saling berdiskusi dalam menentukan skala prioritas dan strategi pembangunan yang akan berjalan, sementara warga desa tidak lagi dipusingkan dengan ketersediaan dana karena berdasarkan amanat Undang-Undang Desa No 6 tahun 2014 pemerintah wajib menggelontorkan dana kepada desa setiap tahunnya. Colaborative governance adalah jawaban dalam proses pembangunan termasuk pembengunan di desa karena memiliki misi transparan dan melibatkan banyak pihak. Collaborative governance adalah serangkaian pengaturan dimana satu atau lebih lembaga publik yang melibatkan secara langsung stakeholders non state di dalam proses pembuatan kebijakan yang bersifat formal, berorientasi konsensi dan deleberatif yang bertujuan untuk membuat atau mengimplemtasikan kebijakan publik atau mengatur program publik atau asset (Ansell and Gash, 2007).

Sebagaimana dikatakan oleh Ansell and Gash, (2007) collaborative governance adalah serangkaian pengaturan dimana satu atau lebih lembaga publik yang melibatkan secara langsung stakeholders non pemerintah di dalam proses pembuatan kebijakan yang bersifat formal, berorientasi konsensus dan deleberatif yang bertujuan untuk membuat atau mengimplementasikan kebijakan publik atau mengatur program publik atau asset. Lebih tegas dikatakan oleh Emerson dkk (2012) menyatakan bahwa collaborative governance merupakan proses dan struktur pembuatan kebijakan publik dan manajemen yang mengajak personal di luar lembaga publik, tingkat pemerintahan dan atau mayarakat, swasta, dan sipil dalam rangka mencapai tujuan publik. Model yang dikemukakan oleh Ansell dan Gash memiliki 4 variabel, yaitu (1) starting condition (kondisi awal), (2) institusional (desain kelembagaan), (3) facilitative leadership (kepemimpinan yang fasilitative) dan (4) collaborative prosses (proses kolaborasi).

\section{METODE PENELITIAN}

Penelitian ini berlokasi di Desa Karangnanas dan Desa Banjaranyar Kecamatan Sokaraja Kabupaten 
Banyumas, adapun sasaran penelitian adalah perangkat desa dan pemangku kepentingan, dan tokoh masyarakat kedua desa tersebut. Teknik pengambilan informan dilakukan secara snowball sampling dengan tetap menjaga independensi dalam mengutarakan pendapat. Metode pengumpulan data dengan wawancara mendalam, pengamatan dan analisis dokumen. Analisis data dilakukan secara interaktif, mulai dari pengumpulan data, kondensasi data, penampilan data, dan penarikan kesimpulan penelitian (Miles dkk, 2013) dan dikombinasikan dengan penampilan data deskriptif.

Untuk menjamin validitas data yang diperoleh dalam penelitian ini dilakukan trianggulasi data. Menurut Patton (dalam Moleong, 2012) trianggulasi sumber dapat dicapai dengan cara membandingkan data hasil pengamatan dengan data hasil wawancara, Membandingkan apa yang dikatakan orang di depan umum dengan apa yang dikatakan secara pribadi dan membandingkan apa yang dikatakan orang-orang tentang situasi penelitian dengan apa yang dikatakannya sepanjang waktu.

\section{HASIL PENELITIAN DAN PEMBAHASAN \\ Deskripsi Lokasi dan Karakteristik Informan}

Desa Karangrau dan Desa Bajaranyarmerupakan desa dalam wilayah Kecamatan Sokaraja Kabupaten Banyumas. Data Desa tahun 2017 menyebutkan bahwa pendudukDesa Karangrau berjumlah 4. 265 jiwa yang terdiri atas 2.160 laki-laki dan 2105 perempuan. Adapun luas wilayahnya 189, 76 hektar yang terdiri dari swawah 45, 5 hektar, tanah pekarangan 67, 45 hektar tanah tegalan atau perkebunan rakyar 67, 89serta peruntukan lainnya seluas 8,92 hektar. Desa Karangrau memiliki 5 Kadus, karena letaknya berdekatan dengan perkotaan maka desa ini berkembang menjadi daerah pemukiman.Karakteritik informan pada penelitian ini terdiri atas Perangkat Desa, Ketua BPD, Ketua LKMD, Ketua RW dan salah seorang tokoh masyarakat desa. Pemilihan tersebut dilakukan secara snowboll sampling dengan pertimbangan mereka mengatahui betul proses kolaborasi dalamprogram dana desa. Terhadap para informan tersebut kemudian dilakukan wawancara mendalam dengan cara mendatangi dari rumah ke rumah.

\section{Anggaran dan Belanja yang berasal dari Dana Desa}

Berdasarkan data sekunder dari laporan pertanggungjawaban Pemerintah Desa Karangrau dalam tulisan ini disusun dengan memilahkan dana yang berasal dari dana desa dan alokasi dana desa dengan dana yang berasal dari pihak lain. Anggaran dan belanja Pemerintah Desa Karangrau yang berasal dari dana desa dan alokasi dana desa tersusun sebagai berikut: 
Tabel 1. Anggaran dan Belanja Pemerintah Desa Karangrau yang berfokus pada dana Desa Tahun 2018

\begin{tabular}{|c|c|c|c|c|}
\hline NO & Uraian & \multicolumn{3}{|c|}{ Jumlah Anggaran } \\
\hline I & JenisPendapatan & Penerimaan & Pengeluaran & Sisa \\
\hline & Dana Desa (DD) & Rp. 788.720 .000 & & \\
\hline II & $\begin{array}{l}\text { Jenis Belanja } \\
\text { A. Bidang Pelaksanaan } \\
\text { Pembangunan Desa } \\
\text { B. Bidang Pemberdayaan } \\
\text { Masyarakat } \\
\text { C. Penyertaan Modal }\end{array}$ & & $\begin{array}{l}\text { Rp } 578.147 .900 \\
\quad(73,30 \%) \\
\text { Rp. } 197.719 .657 \\
(25,01 \%)\end{array}$ & $\begin{array}{r}\text { Rp } 12.852 .425 \\
(1,69 \%)\end{array}$ \\
\hline & JumlahBelanja & - & Rp 755.867.575 & Rp 12.852.425 \\
\hline & Jumlah Pendapatan & Rp 788.720.000 & - & \\
\hline
\end{tabular}

Sumber: Data Sekunder diolah

Selanjutnya anggaran dan alokasi dana desa tersusun sebagai berikut:

belanja Pemerintah Desa Banjaranyar yang berasal dari dana desa dan

Tabel 2. Anggaran dan Belanja Pemerintah Desa Banjaranyar yang berfokus pada dana Desa Tahun 2018

\begin{tabular}{|c|c|c|c|c|}
\hline NO & Uraian & JumlahAnggaran & & \\
\hline \multirow[t]{2}{*}{ I } & Jenis Pendapatan & Penerimaan & Pengeluaran & Sisa \\
\hline & Dana Desa (DD) & Rp. 850.882.000 & & \\
\hline \multirow[t]{3}{*}{ II } & $\begin{array}{ll}\text { Jenis } & \text { Belanja } \\
\text { A. } & \text { Bidang } \\
& \text { Pelaksanaan } \\
& \text { Pembangunan } \\
& \text { Desa } \\
\text { B. } & \text { Bidang } \\
& \text { Pemberdayaan } \\
& \text { Masyarakat } \\
\text { C. } & \text { Penyertaan } \\
& \text { Modal }\end{array}$ & & $\begin{array}{r}\text { Rp514.365.250 } \\
(60,45 \%) \\
\text { Rp. } 326.616 .750 \\
(38,39 \%) \\
\text { Rp. } 19.910 .000 \\
(2,39 \%)\end{array}$ & $\begin{array}{c}\text { Rp. } 5.230 .000 \\
(0,61 \%) \\
\text { Rp. } 21.410 .450 \\
(2,516 \%)\end{array}$ \\
\hline & Jumlah Belanja & - & Rp 824.241.000 & Rp 26.640.450 \\
\hline & Jumlah Pendapatan & Rp 850.882.000 & - & \\
\hline
\end{tabular}

Sumber : Data Sekunder Diolah

Hasil penelitian menunjukan bahwa penggunaan dana desa lebih difokuskan pada pembangunan fisik bukan pada bidang pemberdayaan, sementara amanat undang memberikan penekanan pada bidang pemberdayaan masyarakat.

1. Proses Kolaborasi dalam Kegiatan Pembangunan Desa 


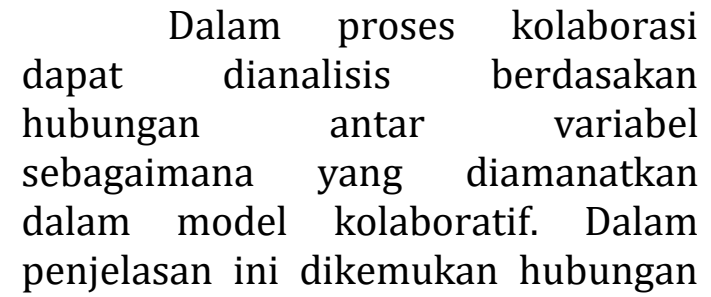

Tabel 3. Hubungan antara Kondisi Awal Program dengan Proses Kolaborasi

\begin{tabular}{|c|c|c|c|c|c|}
\hline \multirow[b]{2}{*}{ No } & \multirow[b]{2}{*}{ Kondisi Awal } & \multicolumn{4}{|c|}{ Proses Kolaborasi } \\
\hline & & Dialog Tatap muka & $\begin{array}{l}\text { Membangun } \\
\text { Kepercayaan }\end{array}$ & Komitmen & Berbagi Pengetahuan \\
\hline 1 & $\begin{array}{l}\text { Sumber } \\
\text { Pengetahuan }\end{array}$ & \begin{tabular}{lr}
\multicolumn{3}{l}{ Kecukupan informasi } \\
dan keterbukaan \\
dalam penggunaan \\
anggaran & dapat \\
memperlacar & dialog \\
tatap muka &
\end{tabular} & $\begin{array}{lr}\text { Pemahaman } & \\
\text { terhadap } & \text { semua } \\
\text { peraturan } & \text { yang } \\
\text { mendasari } & \text { dan } \\
\text { wawasan yang } & \text { luas } \\
\text { diperlukan r untuk } \\
\text { mem-bangun }\end{array}$ & $\begin{array}{l}\text { Komitmen dibentuk } \\
\text { atas dasar keyakinan } \\
\text { orang bahwa para } \\
\text { pemangku kebijakan } \\
\text { di desa memiliki } \\
\text { informasi yang luas }\end{array}$ & $\begin{array}{l}\text { Pemilik pengetahuan } \\
\text { memberikan } \\
\text { gambaran-gambaran } \\
\text { kelebihan dan } \\
\text { kekurangan agar } \\
\text { pihak lain tidak } \\
\text { merasa benar sendiri }\end{array}$ \\
\hline 2 & $\begin{array}{l}\text { Usaha } \\
\text { Mengatasi } \\
\text { Konflik }\end{array}$ & $\begin{array}{l}\text { Untuk mengatasi } \\
\text { konflik yang terjadi } \\
\text { telah disediakan } \\
\text { ruang berdialog yang } \\
\text { disebut Musyawarah } \\
\text { Desa (Musdes) }\end{array}$ & $\begin{array}{ll}\text { Kepercayaan } & \text { harus } \\
\text { dibangun } & \text { terus- } \\
\text { menerus } & \text { untuk } \\
\text { menutup } & \text { ruang } \\
\text { untuk konflik } & \end{array}$ & $\begin{array}{lr}\text { Proses berakhirnya } \\
\text { konflik } \quad \text { karena } \\
\text { masyarakat dan } \\
\text { stakeholder } \\
\text { mengembangkan } \\
\text { komitmen }\end{array}$ & $\begin{array}{l}\text { Praktek baik dan } \\
\text { buruk adanya konflik } \\
\text { telah dielaborasi agar } \\
\text { menasyarkat } \\
\text { mengerti akibat yang } \\
\text { terjadi }\end{array}$ \\
\hline
\end{tabular}

Sumber: Hasil wawancara dan diolah

2. Hubungan antara proses kolaborasi dengan outcomes (hasil guna) dalam kolaborasi

Dalam pelaksanan kegiatan pembangunan proses kolaborasi memberikan manfaat bagi dampak pembangunan fisik dan non fisik.

Dengan dibukanya dialog antara pemerintah desa dan pemangku kepentingan, hal ini menciptakan kepuasan masyarakat untuk menerima pilihan atau keputusan tentang alokasi dana desa.

Dialog juga mendorong pembangunan kepercayaan (trustbuilding). Dengan dialog, masingmasing pihak memiliki kesempatan untuk mendiskusikan kepentingan masing-masing. Hal ini mendorong terjadinya proses kesadaran pentingnya untuk melakukan efisiensi penggunaan dana desa. Artinya, dana desa yang terbatas betul betul dimanfaatkan untuk antar variabel tersebut yaitu hubungan antara kondisi awal dengan proses kolaborasi dan proses kolaborasi dengan hasil guna dalam kolaborasi. 
perencanaan hingga pemanfaatan hasil-hasil pembangunan desa.

Kolaborasi berarti juga pemberdayaan. Pembangunan desa yang berorientasi pada pemberdayaan masyarakat juga telah mendorong pembentukan komitmen dan kepercayaan publik. Proses perencanaan pembangunan menjadi semakin transparan dan akuntabel. Temuan penelitian ini mendukung studi yang telah dilakukan oleh Wardani dan Utami (2020) yang menemukan adanya korelasi antara pemberdayaan masyarakat dan transparansi dalam pengelolaan dana desa.

Kolaborasi dalam pembangunan desa juga terbukti dapat meningkatkan kepuasan masyarakat karena masyaraat terlibat dalam proses perencanaan. Dengan keterlibatan dalam perencanaan maka masyarakat ikut memonitor dan mengevaluasi implementasi program. Hal ini berdampak terhadap efektivitas program dalam menjawab kebutuhan masyarakat. Studi ini mendukung studi yang dilakukan oleh Zeho et al. (2020) yang menyoroti pentinya kolaborasi stakeholder dalam proses pembangunan desa.

Tabel 4. Hubungan antara Proses Kolaborasi dengan Hasil Guna terhadap Masyarakat

\begin{tabular}{|c|c|c|c|}
\hline \multirow[t]{2}{*}{ No } & \multirow[t]{2}{*}{ Proses Kolaborasi } & \multicolumn{2}{|l|}{ Outcome (Hasil Guna) Dana Desa } \\
\hline & & Hasil Sementara & Manfaat Program \\
\hline 1 & Dialog Tatapmuka & $\begin{array}{l}\text { Pekerjaan fisik dan non fisik } \\
\text { terselesaikandengan } \\
\text { waktu }\end{array}$ & $\begin{array}{l}\text { Kepuasan dalam menerima } \\
\text { keputusan karena harapan } \\
\text { masyarakat terpenuhi }\end{array}$ \\
\hline 2 & Membangun Kepercayaan & $\begin{array}{l}\text { Adanya kesadaran masyarakat } \\
\text { bahwa penggunaandana desa } \\
\text { efisien dan } \\
\text { percayaakankemampuanpara } \\
\text { stakeholders }\end{array}$ & $\begin{array}{lr}\text { Rasa curiga dan } & \text { iri hati } \\
\text { berkurang } & \text { karena } \\
\text { pembangunan } & \\
\text { dilaksanakan } & \text { secara } \\
\text { merata } & \end{array}$ \\
\hline 3 & Komitmen & $\begin{array}{l}\text { Partisipasi } \\
\text { masyarakatmeningkat }\end{array}$ & $\begin{array}{l}\text { Pola pemeliharaan } \\
\text { bersama terhadap hasil- } \\
\text { hasil pembangunan }\end{array}$ \\
\hline 4 & Berbagi Pengetahuan & $\begin{array}{l}\text { Pengetahuanmasyarakat dan } \\
\text { para pemangku } \\
\text { kepentingansemakin pandai } \\
\text { dalam pengelolaandana desa }\end{array}$ & \begin{tabular}{lc} 
Mayarakat & telah berfikir \\
untuk & \multicolumn{1}{c}{ senantiasa } \\
meningkatkankualitas \\
program & mulai dari \\
kegiatan & perencanaan \\
sampai & pelaksanaan \\
proyek &
\end{tabular} \\
\hline
\end{tabular}


KESIMPULAN

Dari uraian yang cukup luas mengenai hasil penelitian tentang model kolaborasi dalam pengelolaan dana desa di Desa Karangrau Kabupaten Banyumas, dapat disimpulkan sebagai berikut

1. Proses kolaborasi yang telah berjalan dilihat dari adanya dialog tatap muka, membangun kepercayaan, komitmen masyarakat dan berbagai pemahaman menghasilkan perencanaan dan pelaksanaan pembangunan yang berdimensi pada kebutuhan masyarakat. Hasil program dirasakan oleh masyarakatnya dalam bentuk berkembangnya infrastruktur fisik desa dan usaha pemberdayaan masyarakat.

2. Kepemimpinan kepala desa dan aparatur desa masih menjadi faktor penting dalam menentukan agenda kebijakan desa dan pola keterlibatan masyarakat.

\section{PENGHARGAAN}

Penelitian ini didanai dengan sumber dana BLU Universitas Jenderal Soedirman pada 2019.

\section{REFERENSI}

Ansell, C., \& Gash, A. (2007). Collaborative Governance in Theory and Practice. Journal of Public Administration Research and Theory, 18, 543571. doi:10.1093/jopart/mum032

Emerson, K., Nabatchi, T., \& Balogh, S. (2012). An Integrative Framework for Collaborative Governance, Journal of Public Administration Research and Theory, Volume 22, Issue 1, 1-
29, https://doi.org/10.1093/jopa rt/mur011

Miles, M.B., Huberman, A.M., \& Saldaña, J. (2013). Qualitative data analysis: A methods sourcebook. Thousand Oaks, CA: Sage Publications.

Moleong, L. J. (2012). Metodologi Penelitian Kualitatif. Bandung : PT Remaja Rosdakarya.

Soleh, C. (2014). Dialektika Pembangunan dengan Pemberdayaan. Bandung: Fokusmedia.

Wardani, D., \& Utami, R. R. (2020). Pengaruh transparansi pengelolaan keuangan dana desa dan pemberdayaan masyarakat terhadap kesejahteraan masyarakat desa sidoharjo. Kajian Bisnis Sekolah Tinggi Ilmu Ekonomi Widya Wiwaha, 28(1), 35 - 50. https://doi.org/10.32477/jkb.v2 $\underline{8 \mathrm{i} 1.36}$.

Zeho, F., Prabowo, A., Estiningtyas, R., Mahadiansar, M., \& Sentanu, I. (2020).

Stakeholder collaboration to support accountability in village fund management and rural development. Journal of Socioeconomics and Development, 3(2), 12-22. doi:http://dx.doi.org/10.31328/j sed.v3i2.1395 